\title{
Association of the state hope and decisional conflict with the outcomes of an educational intervention to decrease cardiovascular risk in women: mixed methods study in primary health care
}

Slavica Juric Petricevic ( $\nabla$ slavica.juric01@gmail.com )

Klinicki Bolnicki Centar Split https://orcid.org/0000-0001-8851-7810

Ivancica Pavlicevic

Sveuciliste u Splitu Medicinski fakultet

Natasa Mrduljas-Dujic

Sveuciliste u Splitu Medicinski fakultet

Liza Curcic

Sveuciliste u Splitu Medicinski fakultet

Sanja Dosen Jankovic

Sveuciliste u Splitu Medicinski fakultet

Slavica Skrabic

Family Practice Office in Split

Anita Tolic Biocina

Family Practice Office in Split

Mario Malicki

Sveuciliste u Splitu Medicinski fakultet

Ivan Buljan

Sveuciliste u Splitu Medicinski fakultet

Matko Marusic

Sveuciliste u Splitu Medicinski fakultet

Ana Marusic

Sveuciliste u Splitu Medicinski fakultet

Research article

Keywords: Cardiovascular risk, patient education, hope, decisional conflict, women

Posted Date: July 21st, 2020 
DOI: https://doi.org/10.21203/rs.3.rs-28912/v1

License: (a) (i) This work is licensed under a Creative Commons Attribution 4.0 International License. Read Full License 


\section{Abstract}

\section{Background}

Patient education in lifestyle changes has a positive effect on health in individuals with cardiovascular (CV) risk. We analyzed the effect of an educational intervention on women with different menopausal status in relation to their decisional conflict (DC) about treatment for CV risk and hope that their health will improve according to desired expectations.

\section{Methods}

This prospective interventional follow-up study exposed women to the intervention consisted of a 60minute lecture on the change of lifestyle and nutrition habits to reduce CV risk. We measured the 10-year risk of fatal cardiovascular disease (CVD) and parameters that increase CV risk, the participants filled in 3 questionnaires and six months after the intervention we collected the participants' feedback on the intervention.

Results

Out of 104 participants, 102 (98\%) completed the study. The intervention significantly decreased the 10year risk of fatal CVD at three months from median $3.3(95 \% \mathrm{Cl}=2.6-4.3)$ to $2.9(95 \% \mathrm{Cl}=2.2-3.6)(P<$ $0.001)$ regardless of their menopausal status. The intervention decreased decisional conflict for all respondents after the intervention, and it remained significantly lower at 3 months, but the overall state hope did not change. Two predictive factors of reduced CV risk were identified: high 10-year risk of fatal CVD at the beginning of the study $(\mathrm{OR}=1.58,95 \% \mathrm{Cl} 1.15-2.13)$ and smoking status before the intervention $(\mathrm{OR}=4.05,95 \% \mathrm{Cl} 1.07-15.51)$.

\section{Conclusions}

A brief educational intervention may be effective in reducing CV risk. Hope and decisional conflict seem not to contribute to $\mathrm{CV}$ risk reduction, as only poor health and smoking habits were predictive of risk reduction success.

Trial registration

Trial was retrospectively registrated in CT.gov in February 28th 2019.

Number of protocol: IP-2014-09-7672. Number of registration: NCT03863210.

\section{Background}

It is well-known that lifestyle changes in individuals with cardiovascular (CV) risk factors have a positive effect on their health, survival and prevention of major clinical events $(1,2)$. Smoking and excess body 
weight are the major risk factors that should be targeted with greatest priority in primary CV prevention strategies (1).

The effects of smoking reduction, improving in diet and physical activity on the cardiovascular disease (CVD) risk demonstrate the importance of the lifestyle and dietary change in preventing CVD $(2,3)$.

Several Cochrane systematic reviews on the clinical significance of general dietary changes to reduce CV risk showed that the interventions in the form of advice towards risk factors could decrease CV risk, but that evidence is limited because of the small sample sizes and short term monitoring in included primary studies (4-7).

Patient education can contribute to changing behavior and improving compliance with the prescribed preventive and therapeutic measures $(8,9)$. An important approach for informing the patients and involving them in their health care is defined as shared-decision making (SDM) - a decision-making process jointly shared by patients and their health care provider $(10,11)$. It can be assessed through a decisional conflict (DC), defined as the uncertainty on which course of action to take when choice among competing actions involves risk, loss, regret or challenge to personal life values (12). Another factor that may influence the adherence to a specific treatment is hope that a specific intervention will actually achieve its intended goal $(13,14)$, which has been positively correlated with the quality of life and has a positive effect on individuals dealing with illness or illness events (15).

Despite current positive evidence about lifestyle and dietary change in the prevention of CVD, the recommendations are still not consistently and optimally applied to women, particularly in relation to their menopausal status. More information is needed about factors that will support effective implementation of educational interventions for decreasing CV risk. The aim of our study was to analyze the effect of an educational intervention, presented as a 60-minute lecture in primary health care setting about CV risk factors to women with different menopausal status, in relation to their decisional conflict about their treatment for $\mathrm{CV}$ risk and hope that their health will improve according to desired expectations.

\section{Methods}

\section{Study design}

We performed a prospective interventional follow-up study. We also collected qualitative feedback from the study participants with post intervention survey to explain and interpret the data from the quantitative analysis, and with logistic regression we determine the factors contributing to the success in reducing CV risk.

\section{Setting}

The study took place in family medicine (FM) offices from 1 March to 1 September 2014. Two FM offices were in the city of Split, the capital of the Split-Dalmatian County, one office in the neighboring Adriatic 
island of Brač and one in the southern Adriatic island of Korčula.

\section{Recruiting participants}

In these FM offices there were 781 women in age 45 to 60 . All patients responding to the inclusion criteria listed below are called by telephone or directly contacted in FM offices.

\section{Inclusion criteria}

The eligibility criteria were: female sex, age 45 to 60 years, with one or more CV risk factors [overweight or obesity, i. e. body mass index (BMI) $\geq 25 \mathrm{~kg} / \mathrm{m}^{2}$, and/or central obesity - waist circumference $\geq 88 \mathrm{~cm}$, high blood pressure (systolic blood pressure $\geq 140 \mathrm{~mm} \mathrm{Hg}$ and/or diastolic blood pressure $\geq 90 \mathrm{~mm} \mathrm{Hg}$ ), high blood cholesterol ( $\geq 5.2 \mathrm{mmol} / \mathrm{L}$ ) and active smoking]. The participants on antihypertensive therapy were also included in the study.

All eligible participants were followed for 3 months after the educational intervention, and qualitative data we collected at 6 months.

\section{Exclusion criteria}

The participants with a current CVD (ischemic heart disease, peripheral artery disease, and stroke) were excluded. The participants with malignant diseases and serious systemic or mental diseases were also excluded.

\section{Stratification of the participants according to the reproductive status}

All participants reported their most recent menstrual period. To assess the impact of reproductive status, we used the categorization proposed by the "Stages of Reproductive Aging Workshop" (STRAW) (16): 1) premenopausal (PRE) women - last period reported within 61 days before the intervention; 2) perimenopausal (PERI) women - last period reported 61-365 days before the intervention; and 3) postmenopausal (POST) women - last period reported more than 365 days before the intervention.

\section{Intervention}

All participants were exposed to the intervention. The intervention consisted of a 60-minute lecture titled "Change of lifestyle and nutrition habits to reduce cardiovascular risk". The lecture was delivered in family medicine offices by four specialists of family medicine individually to the groups of 6-8 participants. The lecture was verbal, harmonized among four family physicians, and contained instructions for changing nutrition habits, smoking habits and instructions for increasing physical activity. At the end of the lecture, each participant received a personally tailored decision aid, which included the list of her risk factors, assessment of the 10-year risk of fatal CVD (based on the data provided by the participants before the lecture), and instructions on what she should do in terms of changing the lifestyle habits.

\section{Outcomes}


The study participants first completed the Pre-study questionnaire (Questionnaire 1), which included: a) demographic data (Supplement 1), b) attitudes and knowledge questionnaire about CV risk factors (17) (Supplement 1), c) decisional conflict scale (DCS) $(12,18)$, d) integrative hope scale (IHS) $(13,19)$, and e) eating habits questionnaire (EPAT) (20).

Attitudes and knowledge questionnaire about CV risk factors was created according to the model of "Ottawa Decision Support Tutorial" (17).

The DCS consist of 16 items rated in a 5-point Likert-type response format, and measures individual's uncertainty toward a course of action. There are five subscales: uncertainty, informed, values clarity, support and effective decision. The scores on the total scale and subscales are calculated as a sum of items, divided by the number of items and multiplied by 25 , allowing for a score range from zero (no decisional conflict) to 100 points (extreme decisional conflict) (12). The Croatian version of the scale was previously validated (18).

The IHS is 23-items scale, a self-rating instrument with items being rated on a six-point Likert scale from 1 , strongly disagree, to 6 , strongly agree. It provides an overall score and four dimension scores, obtained by summing up the individual item scores, with negative items being rated inversely. This produces possible overall hope scores ranging from 23 to 138 with higher scores representing higher hopefulness. The scores for the sub-dimensions vary according to the number of items (13). The Croatian version of the scale was previously validated (19). Hope to be healthy at 70 and hope to reduce $\mathrm{CV}$ risk was assessed by a visual analogue scale from 0 to 100 .

EPAT is a simple, quick, self-administered tool using an easy scoring method for accurately assessing fat and cholesterol intake. It is a reliable and valid substitute for more time-consuming food records. EPAT also provides an efficient way to monitor eating patterns of patients over time and is arranged to provide an educational message that reinforces the consumption of recommended types and numbers of servings of low-fat foods (20). The questionnaire was translated into Croatian by the authors and then back translated by an independent language expert to confirm the translation validity.

Ten-year risk of fatal CVD was estimated using the ACC/AHA (American College of Cardiology/American Heart Association) guidelines (21), based on the following data collected from the study participants: age, gender, race, total and HDL (high-density lipoprotein) cholesterol, systolic blood pressure, data about antihypertensive therapy, diabetes mellitus and smoking status.

Immediately after the lecture, the participants filled the Post-lecture questionnaire (Questionnaire 2), which included: a) attitudes and knowledge about CV risk factors (17) (Supplement 2), b) decisional conflict scale (DCS) $(12,18)$ and c) integrative hope scale (IHS) $(13,19)$.

Three months after the lecture, the participants filled in the last questionnaire (Questionnaire 3), which included: a) attitudes and knowledge about CV risk factors (17) (Supplement 3), b) decisional conflict 
scale (DCS) $(12,18), c)$ integrative hope scale (HIS) $(13,19)$ and d) eating habits questionnaire (EPAT) (20). Ten-year risk of fatal CVD was also calculated at this time point.

BMI, waist and hip circumference, systolic and diastolic blood pressure, blood cholesterol, triglycerides, physical activity and smoking status were measured at each of three time points.

\section{Thematic analysis of answers from post-intervention survey}

Six months after the intervention, we contacted the participants for the final assessment, along with their feedback on the intervention in general and their personal opinions on further improvements in their lifestyle. This feedback was in the form of post-intervention survey conducted by the authors. The survey included 13 structured questions and 4 open-ended questions (Supplement 4).

We preformed the thematic analysis of the answers, grouping them into theme categories. Categorization of the answers was made by the two independent assessors. After determining the categories, each answer was marked $\mathrm{s} 1$ if matching to specific category or as 0 if not. Answers were used as predictors in further analysis.

After the study, we grouped the participants into those who reduced the CV risk and those that did not. We used logistic regression for all parameter we measured to identify factors contributing to the reduction in CV risk.

\section{Statistical analysis}

Chi square test was used to compare categorical variables (presented as absolute numbers and percentages). For continuous variables, presented as means with $95 \%$ confidence intervals, we used Mann-Whitney $\mathrm{U}$ test. $P$ values $\leq 0.05$ were considered statistically significant. Logistic regression was used to describe the relationships between variables. Odds ratio for each outcome were reported with $95 \%$ confidence interval. All statistical analyses were conducted using the MedCalc statistical program (version 16.2.1 MedCalc Software, Ostend, Belgium).

\section{Results}

In four FM offices were 781 women in age 45 to 60 . Out of 104 participants who entered the study, 102 (98\%) completed the study. According to their reproductive status, 29 (28.4\%) were premenopausal, 23 (22.5\%) perimenopausal and $50(49.1 \%)$ postmenopausal.

Postmenopausal participants were older than premenopausal and perimenopausal participants, and had greater waist and hip circumference, and higher systolic and diastolic blood pressure. These participants also had significantly higher 10-year risk of fatal CVD $(P=0.004)$ (Table 1). 
Table 1

Baseline characteristics of women with cardiovascular risk enrolled in the study

\begin{tabular}{|c|c|c|c|c|c|}
\hline Parameter & $\begin{array}{l}\text { Total }(n \\
=102)\end{array}$ & $\begin{array}{l}\text { Premenopausal } \\
(n=29 ; 28.4 \%)\end{array}$ & $\begin{array}{l}\text { Perimenopausal } \\
(n=23 ; 22.5 \%)\end{array}$ & $\begin{array}{l}\text { Postmenopausal } \\
(n=50 ; 49.0 \%)\end{array}$ & $P *$ \\
\hline Age (years) & $\begin{array}{l}52.0 \\
(50.0- \\
53.0)\end{array}$ & $\begin{array}{l}49.0(47.0- \\
50.0)\end{array}$ & $51.0(50.0-52.0)$ & $54.0(53.0-55.0)$ & $<.001$ \\
\hline $\begin{array}{l}\text { Body mass index } \\
\left(\mathrm{kg} / \mathrm{m}^{2}\right) \dagger\end{array}$ & $\begin{array}{l}27(25- \\
28)\end{array}$ & $26(25-28)$ & $30(27-33)$ & $28(27-30)$ & 0.111 \\
\hline $\begin{array}{l}\text { Waist } \\
\text { circumference } \\
\text { (cm) }\end{array}$ & $\begin{array}{l}91.0 \\
(86.0- \\
95.0)\end{array}$ & $\begin{array}{l}85.0(81.0- \\
90.0)\end{array}$ & $\begin{array}{l}95.0(88.0- \\
101.0)\end{array}$ & $94.0(90.0-98.0)$ & 0.015 \\
\hline $\begin{array}{l}\text { Hips } \\
\text { circumference } \\
\text { (cm) }\end{array}$ & $\begin{array}{l}107.0 \\
(106.0- \\
111.0)\end{array}$ & $\begin{array}{l}104.0(100.0- \\
108.0)\end{array}$ & $\begin{array}{l}115.0(109.0- \\
120.0)\end{array}$ & $\begin{array}{l}111.0(107.0- \\
114.0)\end{array}$ & 0.005 \\
\hline Waist/Hip ratio & $\begin{array}{l}0.84 \\
(0.81- \\
0.86)\end{array}$ & $0.8(0.8-0.8)$ & $0.8(0.8-0.9)$ & $0.9(0.8-0.9)$ & 0.119 \\
\hline $\begin{array}{l}\text { Systolic blood } \\
\text { pressure (mm } \\
\mathrm{Hg})\end{array}$ & $\begin{array}{l}130.0 \\
(130.0- \\
140.0)\end{array}$ & $\begin{array}{l}127.0(122.0- \\
133.0)\end{array}$ & $\begin{array}{l}135.0(127.0- \\
142.0)\end{array}$ & $\begin{array}{l}140.0(135.0- \\
146.0)\end{array}$ & 0.010 \\
\hline $\begin{array}{l}\text { Diastolic blood } \\
\text { pressure (mm } \\
\mathrm{Hg})\end{array}$ & $\begin{array}{l}85.0 \\
(80.0- \\
90.0)\end{array}$ & $\begin{array}{l}82.0(78.0- \\
85.0)\end{array}$ & $84.0(80.0-88.0)$ & $88.0(85.0-91.0)$ & 0.011 \\
\hline $\begin{array}{l}\text { Total cholesterol } \\
(\mathrm{mmol} / \mathrm{L})\end{array}$ & $\begin{array}{l}6.1(5.9- \\
6.4)\end{array}$ & $6.0(5.6-6.4)$ & $6.3(6.0-6.7)$ & $6.2(6.0-6.5)$ & 0.379 \\
\hline $\begin{array}{l}\text { HDL cholesterol } \\
(\mathrm{mmol} / \mathrm{L})\end{array}$ & $\begin{array}{l}1.5(1.4- \\
1.6)\end{array}$ & $1.5(1.4-1.6)$ & $1.6(1.4-1.7)$ & $1.6(1.5-1.7)$ & 0.561 \\
\hline $\begin{array}{l}\text { Total/HDL } \\
\text { cholesterol } \\
\text { (mmol/L) }\end{array}$ & $\begin{array}{l}4.1(3.8- \\
4.5)\end{array}$ & $4.2(3.8-4.7)$ & $4.3(3.9-4.7)$ & $4.1(3.8-4.4)$ & 0.853 \\
\hline $\begin{array}{l}\text { Non-HDL } \\
\text { cholesterol } \\
\text { (mmol/L) } \ddagger\end{array}$ & $\begin{array}{l}4.6(4.4- \\
5.0)\end{array}$ & $4.5(4.1-4.9)$ & $4.8(4.5-5.1)$ & $4.7(4.4-5.0)$ & 0.571 \\
\hline
\end{tabular}

*Differences between premenopausal, perimenopausal and postmenopausal group of women are presented with chi square for categorical data and Mann-Whitney for continuous data.

†The individual's body mass divided by the square of their height.

¥Non-HDL-C measures all atherogenic apolipoprotein B-containing lipoproteins, including low-density lipoprotein cholesterol (LDL-C), very low-density lipoprotein cholesterol, and to a lesser extent, intermediate-density lipoprotein cholesterol, lipoprotein (a), chylomicrons, and chylomicron remnants.

$\S 10-y e a r$ risk of fatal cardiovascular disease was estimated using ACC/AHA guidelines (21). 


\begin{tabular}{|c|c|c|c|c|c|}
\hline Parameter & $\begin{array}{l}\text { Total }(n \\
=102)\end{array}$ & $\begin{array}{l}\text { Premenopausal } \\
(n=29 ; 28.4 \%)\end{array}$ & $\begin{array}{l}\text { Perimenopausal } \\
(n=23 ; 22.5 \%)\end{array}$ & $\begin{array}{l}\text { Postmenopausal } \\
(n=50 ; 49.0 \%)\end{array}$ & $P^{*}$ \\
\hline LDL (mmol/L) & $\begin{array}{l}4.1(3.8- \\
4.4)\end{array}$ & $3.9(3.4-4.3)$ & $4.0(3.7-4.4)$ & $4.3(3.9-4.6)$ & 0.297 \\
\hline $\begin{array}{l}\text { Triglycerides } \\
(\mathrm{mmol} / \mathrm{L})\end{array}$ & $\begin{array}{l}1.4(1.3- \\
1.4)\end{array}$ & $1.4(1.2-1.6)$ & $1.6(1.2-2.0)$ & $1.5(1.3-1.7)$ & 0.598 \\
\hline $\begin{array}{l}\text { Fasting glucose } \\
(\mathrm{mmol} / \mathrm{L})\end{array}$ & $\begin{array}{l}4.9(4.7- \\
5.3)\end{array}$ & $5.0(4.6-5.3)$ & $5.1(4.7-5.5)$ & $5.4(5.0-5.8)$ & 0.299 \\
\hline $\begin{array}{l}\text { Physical activity } \\
\text { (hours per day) }\end{array}$ & $\begin{array}{l}0.4(0.5- \\
2-0.5)\end{array}$ & $0.5(0.2-0.7)$ & $0.6(0.3-0.8)$ & $0.6(0.3-0.9)$ & 0.860 \\
\hline \multicolumn{6}{|l|}{ Smoking (n): } \\
\hline Non smoker & $\begin{array}{l}46 \\
(45.1 \%)\end{array}$ & $11(23.9 \%)$ & $8(17.3 \%)$ & 27 (58.6\%) & \multirow[t]{4}{*}{0.196} \\
\hline Ex-smoker & $\begin{array}{l}11 \\
(10.8 \%)\end{array}$ & $5(45.4 \%)$ & 4 (36.3\%) & $2(18.1 \%)$ & \\
\hline Smoker & $\begin{array}{l}44 \\
(43.1 \%)\end{array}$ & $12(27.2 \%)$ & $11(25.0 \%)$ & $21(47.7 \%)$ & \\
\hline $\begin{array}{l}\text { Occasional } \\
\text { smoker }\end{array}$ & $1(1.0 \%)$ & 1 & 0 & 0 & \\
\hline \multicolumn{5}{|l|}{$\begin{array}{l}\text { Antihypertensive } \\
\text { therapy: }\end{array}$} & \multirow[t]{3}{*}{0.0541} \\
\hline Yes & $\begin{array}{l}35 \\
(34.3 \%)\end{array}$ & $5(14.2 \%)$ & $8(22.9 \%)$ & $22(62.9 \%)$ & \\
\hline No & $\begin{array}{l}67 \\
(65.6 \%)\end{array}$ & 24 (35.8\%) & $15(22.3 \%)$ & $28(41.7 \%)$ & \\
\hline $\begin{array}{l}\text { Cardiovascular } \\
\text { risk§ }\end{array}$ & $\begin{array}{l}3.3(2.6- \\
4.3)\end{array}$ & $2.7(2.1-3.6)$ & $4.2(2.9-5.6)$ & $5.2(4.1-6.2)$ & 0.004 \\
\hline \multicolumn{6}{|c|}{$\begin{array}{l}\text { *Differences between premenopausal, perimenopausal and postmenopausal group of women are } \\
\text { presented with chi square for categorical data and Mann-Whitney for continuous data. }\end{array}$} \\
\hline \multicolumn{6}{|c|}{ †The individual's body mass divided by the square of their height. } \\
\hline \multicolumn{6}{|c|}{$\begin{array}{l}\text { ‡Non-HDL-C measures all atherogenic apolipoprotein B-containing lipoproteins, including low-density } \\
\text { lipoprotein cholesterol (LDL-C), very low-density lipoprotein cholesterol, and to a lesser extent, } \\
\text { intermediate-density lipoprotein cholesterol, lipoprotein (a), chylomicrons, and chylomicron remnants. }\end{array}$} \\
\hline \multicolumn{6}{|c|}{$\S 10$-year risk of fatal cardiovascular disease was estimated using ACC/AHA guidelines (21). } \\
\hline
\end{tabular}

In the group of postmenopausal participants, 22 (62.9\%) women had already been taking antihypertensive therapy. In the group of premenopausal participants, $5(14.2 \%)$ had already been taking antihypertensive therapy and $8(22.9 \%)$ in the group of perimenopausal participants (Table 1$)$. 
The intervention decreased 10-year risk of fatal CVD at three months $(P<0.001)($ Table 2$)$ in all participants without any differences between the groups according to their menopausal status.

Table 2

Cardiovascular risk, decisional conflict* about lifestyle change and state hopet before and after intervention ( $\mathrm{N}=102)$

\begin{tabular}{|c|c|c|c|c|}
\hline $\begin{array}{l}\text { Parameter (median, } \\
95 \% \mathrm{Cl} \text { ) }\end{array}$ & $\begin{array}{l}\text { At } \\
\text { recruitment }\end{array}$ & $\begin{array}{l}\text { Immediately after } \\
\text { intervention }\end{array}$ & $\begin{array}{l}\text { 3-months after } \\
\text { intervention }\end{array}$ & $P \ddagger$ \\
\hline \multicolumn{5}{|l|}{ Total } \\
\hline Cardiovascular risk & $\begin{array}{l}3.3(2.6- \\
4.3)\end{array}$ & - & $2.9(2.2-3.6)$ & $\begin{array}{l}< \\
0.001\end{array}$ \\
\hline Decisional conflict & $36(33-40)$ & $23(20-26)$ & $27(25-30)$ & $\begin{array}{l}< \\
0.001\end{array}$ \\
\hline State hope & $\begin{array}{l}104(102- \\
107)\end{array}$ & $107(104-110)$ & $105(102-108)$ & 0.495 \\
\hline $\begin{array}{l}\text { Hope to be healthy at } \\
70\end{array}$ & $68(64-72)$ & $70(66-74)$ & $68(63-72)$ & 0.769 \\
\hline Hope to reduce CVR & $63(58-68)$ & $68(63-72)$ & $68(63-72)$ & 0.157 \\
\hline Weight (kg) & $61(54-68)$ & $61(54-68)$ & $61(54-68)$ & 0.007 \\
\hline $\begin{array}{l}\text { Waist circumference } \\
(\mathrm{cm})\end{array}$ & $92(89-94)$ & $92(89-94)$ & $89(87-92)$ & $<.001$ \\
\hline $\begin{array}{l}\text { Hips circumference } \\
\text { (cm) }\end{array}$ & $\begin{array}{l}110(107- \\
112)\end{array}$ & $110(107-112)$ & $107(105-110)$ & $\begin{array}{l}< \\
0.001\end{array}$ \\
\hline \multicolumn{5}{|c|}{ *According to the Ottawa decisional conflict scale $(12,18)$. } \\
\hline \multicolumn{5}{|c|}{$\begin{array}{l}\text { †State hope was assessed using the Integrative Hope Scale, while hope to be healthy at } 70 \text { and to } \\
\text { reduce CVR was assessed by visual analogue scale from } 0 \text { to } 100(13,19) \text {. }\end{array}$} \\
\hline \multicolumn{5}{|l|}{$\ddagger$ ‡ruskal Wallis test. } \\
\hline
\end{tabular}

The intervention affected the decisional conflict for all respondents, with a significant initial decrease immediately after the intervention. It increased again at three months, but it was still significantly lower than before the intervention $(P<0.001)$ (Table 2).

The overall state hope did not change after the intervention, even after 3 months $(P=0.497)$ (Table 2$)$. There was no statistical difference in hope among three groups of participants according to their menopause status at the beginning of the study $(P=0.245)$. Immediately after the intervention the lowest state hope was found in the postmenopausal group $(P=0.016)$, which also had the highest 10 -year risk of fatal CVD. 
The analysis of answers from post-intervention survey six months after the active phase of intervention showed that $41(40.2 \%)$ participants thought that the educational intervention was useful, and 35 (34.3\%) asked for more frequent controls, counseling and support. Motivation as an important factor was reported by $21(20.5 \%)$ participants. Twelve (11.7\%) participants recorded reducing in body weight, and 8 $(7.8 \%)$ stated they maintained body weight with exercise. Twelve $(11.7 \%)$ participants reported it was hard to maintain healthy habits with daily obligations. Sixteen (15.6\%) participants did not provide answers.

We identified 31 participants who significantly reduced $C V$ risk and 31 participants whose $C V$ risk did not change. There were no difference between the two groups in clinical parameters except in hip circumference, blood pressure and smoking status (more non-smokers in the first group and more exsmokers in the second group) (Table 3 ). 
Table 3

Differences between respondents who reduced CV risk and those whose risk remained the same

\begin{tabular}{|c|c|c|c|}
\hline Parameter & $\begin{array}{l}\text { Reduced CVD risk }(n= \\
\text { 31) }\end{array}$ & $\begin{array}{l}\text { Not reduced CVD risk }(\mathrm{n}= \\
31 \text { ) }\end{array}$ & $P *$ \\
\hline Age (years) & $53.0(50.0-55.0)$ & $52.0(50.0-53.4)$ & 0.682 \\
\hline Body mass index $\left(\mathrm{kg} / \mathrm{m}^{2}\right)$ & $27.0(24.8-28.4)$ & $28.7(25.5-33.1)$ & 0.271 \\
\hline Waist circumference (cm) & $89.0(85.0-97.4)$ & $97.0(86.4-104.7)$ & 0.168 \\
\hline Hip circumference (cm) & $106.0(104.1-109.5)$ & $113.5(106.5-119.8)$ & 0.035 \\
\hline Waist/Hip ratio & $0.84(0.81-0.87)$ & $0.84(0.80-0.88)$ & 0.969 \\
\hline $\begin{array}{l}\text { Systolic blood pressure (mm } \\
\mathrm{Hg} \text { ) }\end{array}$ & $125.0(120.0-130.0)$ & $140.0(140.0-150.0)$ & 0.001 \\
\hline $\begin{array}{l}\text { Diastolic blood pressure (mm } \\
\mathrm{Hg})\end{array}$ & $80.0(79.2-82.1)$ & $90.0(90.0-90.0)$ & 0.004 \\
\hline Total cholesterol (mmol/L) & $6.0(5.8-6.6)$ & $6.4(6.0-6.9)$ & 0.545 \\
\hline HDL cholesterol (mmol/L) & $1.6(1.4-1.7)$ & $1.4(1.3-1.5)$ & 0.107 \\
\hline $\begin{array}{l}\text { Total/HDL cholesterol } \\
\text { (mmol/L) }\end{array}$ & $4.0(3.4-4.7)$ & $4.5(4.0-4.9)$ & 0.155 \\
\hline Non-HDL cholesterol (mmol/L) & $4.4(4.1-5.1)$ & $5.0(4.5-5.3)$ & 0.328 \\
\hline LDL (mmol/L) & $4.5(3.9-4.9)$ & $4.3(3.7-4.7)$ & 0.827 \\
\hline Triglycerides (mmol/L) & $1.3(1.1-1.5)$ & $1.4(1.1-1.5)$ & 0.706 \\
\hline Fasting glucose (mmol/L) & $4.9(4.5-5.4)$ & $4.9(4.5-5.4)$ & 0.898 \\
\hline Physical activity (hours per day) & $0.4(0.1-0.5)$ & $0.4(0.0-0.5)$ & 0.794 \\
\hline \multicolumn{4}{|l|}{ Smoking (n): } \\
\hline Non smoker & $17(27.4 \%)$ & $5(8.1 \%)$ & \multirow[t]{4}{*}{0.001} \\
\hline Ex-smoker & $9(14.5 \%)$ & $24(38.7 \%)$ & \\
\hline Smoker & $5(8.1 \%)$ & $1(1.6 \%)$ & \\
\hline Occasional smoker & $0(0.0 \%)$ & $1(1.6 \%)$ & \\
\hline \multicolumn{4}{|l|}{ Antihypertensive therapy: } \\
\hline Yes & $9(14.8 \%)$ & $13(21.3 \%)$ & \multirow[t]{2}{*}{0.114} \\
\hline No & $22(36.1 \%)$ & $17(27.3 \%)$ & \\
\hline
\end{tabular}

*Chi square for categorical data and Mann-Whitney for continuous data. 


\begin{tabular}{|llll|}
\hline Parameter & $\begin{array}{l}\text { Reduced CVD risk }(n= \\
\text { 31) }\end{array}$ & $\begin{array}{l}\text { Not reduced CVD risk }(n= \\
\mathbf{3 1})\end{array}$ & $P^{*}$ \\
\hline Cardiovascular risk & $2.6(1.8-4.0)$ & $6.2(4.8-8.1)$ & 0.001 \\
\hline & & \\
\hline *Chi square for categorical data and Mann-Whitney for continuous data. & \\
\hline
\end{tabular}

Multivariate logistic regression identified 2 factors predictive of reduced CV risk at the end of the study: high 10-year risk of fatal CVD at the beginning of the study $(\mathrm{OR}=1.58,95 \% \mathrm{Cl} 1.15-2.13)$ and if the participant was the cigarette smoker $(\mathrm{OR}=4.05,95 \% \mathrm{Cl} 1.07-15.51)$, which explained $50 \%$ of the variance $\left(R^{2}=0.50\right)$.

\section{Discussion}

Our study showed that an intervention in family practice setting, consisting of a 60-minute lecture on change of lifestyle and nutrition habits, was associated with a reduced CV risk in the group of women between 45 and 60 years, but mostly in those women who already had high CV risk and who were regular or occasional cigarette smokers. The participants' overall level of hope and decisional conflict were not related to their success in reducing $\mathrm{CV}$ risk after the intervention.

These results should be considered in view of the limitation that we could not use a control group in the setting where the intervention was delivered. It was organizationally and ethically difficult to perform a methodologically rigorous study in a family medicine practice setting. The strength of this study was that it was a follow-up study of 6 months of a patient cohort and that the follow up was almost complete (98\%). Mentioning a follow-up of 6 months, other studies like Liyana et al. (22) concluded that weight loss related lifestyle modifications over a 6-month period could improve selected cardiometabolic risk factors, particularly fasting glucose, TC and HDL-C in overweight and obese women with favorable sustainability over a 12-month period. Also, we used ACC/AHA guidelines to calculate CV risk based on full set of data collected from the study participants (age, gender, race, total and HDL (high-density lipoprotein) cholesterol, systolic blood pressure, data about antihypertensive therapy, diabetes mellitus and smoking status) (21). Previous studies have indicated that more individuals are recommended for treatment according to the ACC/AHA guidelines than the other guidelines (23).

We were also able to determine the predictors of a successful lifestyle change. The main predictor of decreasing $\mathrm{CV}$ risk after the educational intervention was cigarette smoking. This may indicate that smokers with high $\mathrm{CV}$ risk may benefit the most from the educational intervention used in this research. We explain this with the fact that most important thing that smokers can do to improve and protect their health is to quit smoking, but this is difficult for most of them. However, efforts to improve the health of smokers should not be limited to smoking cessation (24). Due to the evidence which indicate that current interventions for smoking cessation have limited effectiveness (23), further research should aim to identify the factors underlying educational intervention which are useful for smokers. 
Participants with higher $\mathrm{CV}$ risk at the beginning had a higher chance to reduce it in comparison to those with a low $\mathrm{CV}$ risk. Participants with a higher CV risk may have had better awareness about their status, which has been shown to help in reducing of blood pressure, and were more motivated to change their habits (25). Although several studies described the positive role of the self-management in the treatment of chronic conditions like hypertension (26), the effects of these actions have been explored in short terms only. Further research should be focused on long term benefits of self-management in the treatment of chronic conditions.

The waist and hip circumference significantly decreased after the intervention. Some studies reported that central obesity is a better predictor of health events than BMI (27). Although it is not recommended as the measure of primary outcome (27), our data indicate that waist and hip circumference should be useful as secondary measures of $\mathrm{CV}$ risk, along with $\mathrm{BMI}$, because they are low cost and easy to preform, and possibly enable stronger conclusions about the effectiveness of the intervention.

After the intervention, participants in the overall sample have lower result on the decisional conflict scale, meaning that they grew more certain in their decision and choices $(12,18)$. Although there was no control group, it can be assumed that the intervention served as a decision aid, taken into account it was delivered by experts, whose information patients could trust. In other settings, it has been shown that even one-hour video intervention consisting of information about the disease risk can reduce the decisional conflict (25). These results indicate that the focus of interventions should be to make individuals more independent in the search for health information, in order to enable them to make health decisions more easily.

The prevention of CVD requires setting and achieving goals that require both planning and motivation, and so that hope becomes important in this context. However, our results on the association between state hope and CV risk identified that the state hope has nothing to do with CVD risk, but effectiveness of the intervention - hope does not influence the risk. In a recent study, hope also did not directly predict lifestyle changes in individuals with CV risk (28). The participants with high hope and high CVD knowledge scores had a lower probability of visiting a physician because they believed they already possessed the knowledge they needed, thus not investing behavioral effort in this regard (28). The results from our study could thus be explained by losing hope - plus those participants who had lost their hope, and were already aware of their significant CV risk were ready for make changes in their lifestyle.

\section{Conclusion}

In conclusion, we showed that a brief lecture on CVD risks may have a potential to support CV risk reduction. The intervention was relatively easy to implement in a primary practice setting, which is an advantage compared to other interventions, such as smoking cessation advices and diet or exercise strategies (e.g. yoga) $(29,30)$. The participants who reduced their CV risk after the intervention were characterized as those with most difficult CV risk status and those who have better chance to make some 
changes in their lifestyle. The role of decisional conflict and hope in decreasing CVD risk should be further explored to identify possible educational intervention targets.

\section{List Of Abbrevations}

ACC/AHA - American College of Cardiology/American Heart Association

BMI - body mass index

CV risk - cardiovascular risk

CVD - cardiovascular disease

DC - decisional conflict

DCS - decisional conflict scale

FM offices - family medicine offices

EPAT - eating habits questionnaire

HDL cholesterol - high-density lipoprotein

HIS - integrative hope scale

PRE - premenopausal

PERI - perimenopausal

POST - postmenopausal

SDM - shared decision making

STRAW - Stages of Reproductive Aging Workshop

\section{Declarations}

\section{Ethics approval and consent to participate}

The Ethics Committee of the University of Split School of Medicine approved the study. The participants signed an informed consent after receiving information about the study. The study was part of a research project funded by the Croatian Science Foundation No. IP-2014-09-7672.

\section{Consent to publication}

Not relevant. 
Availability of data and materials

The datasets used and/or analyzed during the current study are available from the corresponding author on reasonable request.

\section{Competing interests}

The authors declare they have no competing interests.

\section{Funding}

This study did not receive any specific grant from funding agencies in the public, commercial, or not-forprofit sectors.

\section{Authors' contributions}

This study is part of SJP's PhD. AM and IP are SJP's academic supervisors. All authors contributed to the design of the study. SJP was responsible for data collection and analysis with input from AM and IP. SJP drafted the manuscript, which AM and IP commented on and edited; the final manuscript was read and approved by all authors.

\section{Acknowledgments}

I would like to thank all family medicine doctors for their participation in the study. Specially, I would like to thank prof. dr. sc. Ana Marusic for her help in reviewing this manuscript.

\section{References}

1. Tikk K, Sookthai D, Monni S, et al. Primary preventive potential for stroke by avoidance of major lifestyle risk factors: the European Prospective Investigation into Cancer and Nutrition-Heidelberg cohort. Stroke. 2014;45(7):2041-6.

2. Hu FB, Stampfer MJ, Manson JE, et al. Trends in the incidence of coronary heart disease and changes in diet and lifestyle in women. N Engl J Med. 2000;343(8):530-7.

3. Hu FB, Manson JE, Stampfer MJ, et al. Diet, lifestyle, and the risk of type 2 diabetes mellitus in women. N Engl J Med. 2001;345(11):790-7.

4. Rees K, Dyakova M, Wilson N, Ward K, Thorogood M, Brunner E. Dietary advice for reducing cardiovascular risk. Cochrane Database Syst Rev. 2013;12:CD002128.

5. Hooper L, Martin N, Abdelhamid A, Davey Smith G. Reduction in saturated fat intake for cardiovascular disease. Cochrane Database Syst Rev. 2015;6:CD011737.

6. Adler AJ, Taylor F, Martin N, Gottlieb S, Taylor RS, Ebrahim S. Reduced dietary salt for the prevention of cardiovascular disease. Cochrane Database Syst Rev. 2014;12:CD009217. 
7. Seron P, Lanas F, Pardo Hernandez H, Bonfill Cosp X. Exercise for people with high cardiovascular risk. Cochrane Database Syst Rev. 2014;8:CD009387.

8. Hayes SN. Preventing cardiovascular disease in women. Am Fam Physician. 2006;74(8):1331-40.

9. Smiley WH 3. Getting patients to their lipid targets: a practical approach to implementing therapeutic lifestyle changes. J Am Osteopath Assoc. 2011;111(4 Suppl 3):eS13-7. rd. .

10. Desroches S, Gagnon MP, Tapp S, Legare F. Implementing shared decision-making in nutrition clinical practice: a theory-based approach and feasibility study. Implement SCi. 2008;3:48.

11. Briss P, Rimer B, Reilley $B$, et al. Promoting informed decisions about cancer screening in communities and healthcare systems. Am Journal Prev Med. 2004;26(1):67-80.

12. O'Connor AM. Validation of a decisional conflict scale. Med Decis Making. 1995;15(1):25-30.

13. Schrank B, Woppmann A, Sibitz I, Lauber C. Development and validation of an integrative scale to assess hope. Health Expect. 2011;14(4):417-28.

14. Alberto J, Joyner B. Hope, optimism, and self-care among Better Breathers Support Group members with chronic obstructive pulmonary disease. AppL Nurs Res. 2008;21(4):212-7.

15. Evangelista LS, Doering LV, Dracup K, Vassilakis ME, Kobashigawa J. Hope, mood states and quality of life in female heart transplant recipients. J Heart Lung Transplant. 2003;22(6):681-6.

16. Soules MR, Sherman S, Parrott E, et al. Executive summary: Stages of Reproductive Aging Workshop (STRAW). Climacteric. 2001;4(4):267-72.

17. Ottawa Decision Support Tutorial. The Ottawa Hospital Research Institute; https://decisionaid.ohri.ca/odst/pdfs/odst.pdf.

18. Pavlicevic I, Skrabic S, Malicki M, Mercep AH, Marusic M, Marusic A. Decisional conflict and vaccine uptake: cross-sectional study of 2012/2013 influenza season in Croatia. Arch Med Sci. 2015;11(4):788-95.

19. Malicki M, Markovic D, Marusic M. Association of trait and specific hopes: cross sectional study on students and workers of health professions in Split, Croatia. PeerJ. 2016;4:e1604.

20. Peters JR, Quiter ES, Brekke ML, et al. The Eating Pattern Assessment Tool: a simple instrument for assessing dietary fat and cholesterol intake. J Am Diet Assoc. 1994;94(9):1008-13.

21. Goff DC Jr, Lloyd-Jones DM, Bennett G, et al. 2013 ACC/AHA guideline on the assessment of cardiovascular risk: a report of the American College of Cardiology/American Heart Association Task Force on Practice Guidelines. J Am Coll Cardiol. 2014;63(25):2935-59.

22. Liyana AZ, Appannah G, Sham SYZ, Fazliana M, Nor NSM, Ambak R, et al. Effectiveness of a community-based intervention for weight loss on cardiometabolic risk factors among overweight and obese women in a low socio-economic urban community: findings of the MyBFF@home. BMC Women's Health. 2018;18:126.

23. McClure JB, Divine G, Alexander G, et al. A comparison of smokers' and nonsmokers' fruit and vegetable intake and relevant psychosocial factors. Behav Med. 2009;35(1):14-22. 
24. Fanshawe TR, Halliwell W, Lindson N, Aveyard P, Livingstone-Banks J, Hartmann-Boyce J. Tobacco cessation interventions for young people. Cochrane Database Syst Rev. 2017; 11.

25. Taylor A, Thompson C. Decision aids reduced decisional conflict in patients with newly diagnosed hypertension. Evid Based Nurs. 2004;7(1):17.

26. Sahakyan KR, Somers VK, Rodriguez-Escudero JP, et al. Normal-Weight Central Obesity: Implications for Total and Cardiovascular Mortality. Ann Intern Med. 2015;63(11):827-35.

27. Bosomworth NJ. Normal-weight central obesity. Unique hazard of the toxic waist. Cam Fam Physician. 2019;65(6):399-408.

28. Feldman DB, Sills JR. Hope and cardiovascular health-promoting behaviour: education alone is not enough. Psyhol Health. 2013;28(7):727-45.

29. Chu P, Pandya A, Salomon JA, Goldie SJ, Hunink MG. Comparative Effectiveness of Personalized Lifestyle Management Strategies for Cardiovascular Disease Risk Reduction. J Am Heart Assoc. 2016;5(3):e002737.

30. Dehghani A, Kumar Bhasin S, Dwivedi S, Kumar Malhotra R. Influence of Comprehensive Life Style Intervention in Patients of CHD. Glob J Health Sci. 2015;7(7):6-16.

\section{Supplementary Files}

This is a list of supplementary files associated with this preprint. Click to download.

- supplement4.docx

- supplement3.docx

- supplement2.docx

- supplement1.docx

- STROBEchecklistcrosssectional.docx 